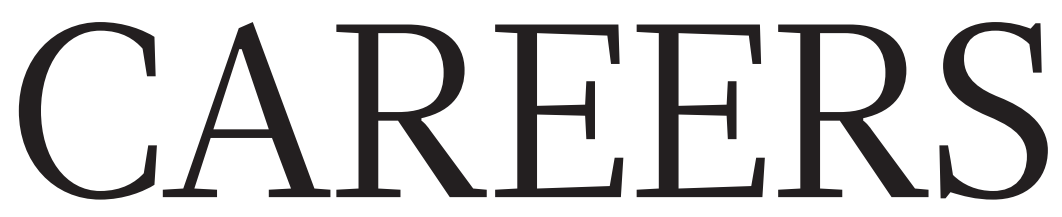

A DIFFERENCE MADE A geohydrologist pays tribute to her PhD supervisor $\mathbf{p . 2 9 7}$

MENTORING Discover tips and resources at go.nature.com/mentor
SOCIAL Follow us on Twitter at twitter.com/naturejobs

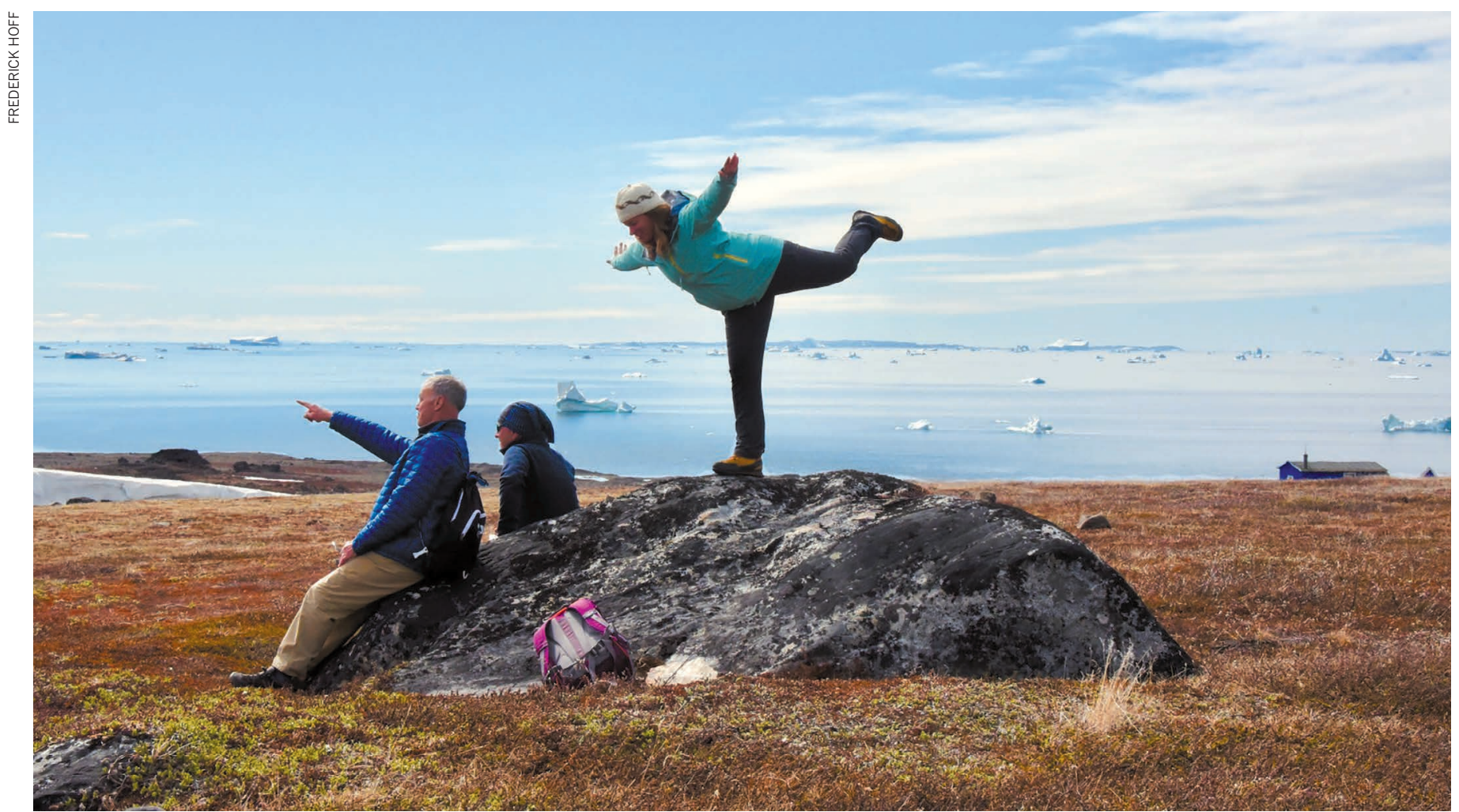

Rock on: Sarah Aciego shows her moves on Disko Island, Greenland, where she explains the effects of climate change to tourists, with Big Chill Adventures.

COMMUNICATION

\title{
Around the world
}

\section{Scientists who work as travel guides enjoy inspiring their guests.}

\section{BY ROBERTA KWOK}

$\mathrm{I}$ n 2013, Sarah Aciego came up with an idea while conducting field research on glaciers in Greenland. Her mother, Mindy Cambiar, is a photographer who had accompanied Aciego to document her team's work. The pair discussed bringing tourists to Greenland and Iceland, where Aciego could explain climate change amid dramatic landscapes. Although Aciego had tried other forms of outreach, such as public lectures, their impact felt limited. "I felt like I was just talking to the same people," says Aciego, then a glaciochemist at the University of Michigan in Ann Arbor. Aciego and Cambiar started a travel company called Big Chill Adventures and issued a press release that resulted in a New York Times story (see go.nature.com/ny_times). During the firm's first trips in 2015, Aciego enjoyed sharing awe-inspiring spectacles, such as the Greenland ice sheet, with travellers. Aciego left her job in Michigan, and now splits her time between Big Chill Adventures and working as a flight instructor and as a part-time adjunct assistant professor for the University of Wyoming in Laramie.

Aciego recognizes that tourism can damage fragile ecosystems and produce high carbon emissions. To minimize harm, she keeps tour groups small, avoids disturbing pristine areas and teaches responsible wilderness practices such as reducing litter. And she hopes that clients leave with a greater awareness of environmental issues. Helen Giacoma, of Dallas, Texas, went to Iceland with Aciego last autumn, and was able to see for herself how far a glacier had retreated over one year. "It just hits you, how real it is", she says. She now follows science news more closely.

Scientists have many options for outreach, ranging from making videos to giving talks. But for some researchers, nothing compares to travelling the globe to show tourists the science behind landscapes, ecosystems or the night sky. These jobs offer opportunities to see new places, revisit beloved spots and communicate to a captive audience over several days. "You're getting paid to travel," says Dominic Rollinson, a senior birdwatching guide at Birding Ecotours in Cape Town, South Africa.

The work isn't a series of holidays, however. Trips can involve long hours, difficult clients and many logistical duties. Long absences from home can strain relationships with family and friends. And the pay is often modest.

The downsides haven't deterred scientists 
- such as Bob Jackson, founder of the travel company Geology Adventures in Ravensdale, Washington, and a former geology consultant. "It has its ups and its downs," he says. "But it is definitely the most fun thing I've ever done."

Tourism has exploded over the past few decades: the United Nations World Tourism Organization in Madrid estimates that the number of international tourist arrivals rose from 531 million to 1.3 billion from 1995 to 2017. Although statistics on science-themed tourism are sparse, signs of growth are emerging. Birding tourism has "gone through the roof" over the past decade, partly as a result of interest in citizen science and the promotion of birding events through social media, says Chris Lotz, founder of Birding Ecotours. According to the United Nations Educational, Scientific, and Cultural Organization in Paris, on average, about eight Global Geoparks - areas with international geological significance - have been established annually over the past decade, and there are currently about 140 such sites worldwide.

Tourists are seeking "a more enriching, educational travel experience", says Tao Tao Holmes, director of trip design and operations at Atlas Obscura - a company based in New York City that runs trips and an online database about places and foods from around the world. This year, about $15 \%$ of the firm's tours have a science or wildlife theme. Holmes says that science-themed trips regularly fill up, and clients often sign up for more afterwards.

Scientists take a variety of paths into the industry. Rollinson led day tours for a birdwatching travel company while he was a $\mathrm{PhD}$ student at the University of Cape Town. Lotz, whom he met through birdwatching circles, then offered him a full-time job. Jackson led geology field trips for elementary school students, and the popularity of these excursions prompted him to start Geology Adventures. He now runs trips full-time for more than 1,500 travellers each year in western North America, Spain and Australia.

Researchers can suggest ideas to travel companies. Atlas Obscura is open to proposals for trips that offer special access or knowledge, Holmes says. For instance, during a Utah trip that the company ran this year with an avian biologist, travellers got to help researchers find tiny and elusive flammulated owls. Partnering with a company can relieve a scientist-guide of some responsibilities; Atlas Obscura takes care of details such as advertising, payments and liability insurance.

Some cruise companies hire biologists, geologists or astronomers to give talks and point out natural phenomena. Ornithologist Samuel Temidayo Osinubi started working for the cruise line Silversea in Monaco, after being recommended by another lecturer. Now a postdoc at the University of Cape Town in South Africa, he spends about two months each year on cruises and has sailed around west Africa, the British Isles, the Arctic and Antarctica.

Communicating science to travellers has advantages over other outreach. People are outside their comfort zone, so the information might make a bigger impact, says Vicky Stein, who has worked as a marine biologist on whale-watching tours for Sanctuary Cruises in Moss Landing, California. And talking faceto-face makes it easier to tackle controversial issues. She says that she has had productive discussions with climate-change sceptics. "It feels like more of a real conversation," says Stein, now a news assistant at PBS NewsHour in Arlington, Virginia. Hands-on activities can inspire children; Michael O'Clair, of Seattle, Washington, says his daughter's interest in geology was "piqued enormously" when he took her on a mineral-collecting trip led by Jackson in 2007. She was seven years old then, and she has continued the hobby ever since.

Long trips also allow for more-nuanced discussions. Jason Goldman, a former animalcognition researcher who is now a freelance science journalist in Los Angeles, California, and travel guide for Atlas Obscura, talks about complex conservation issues during his ecology-themed tours. "It's a sustained, multiday-long conversation with your audience,"

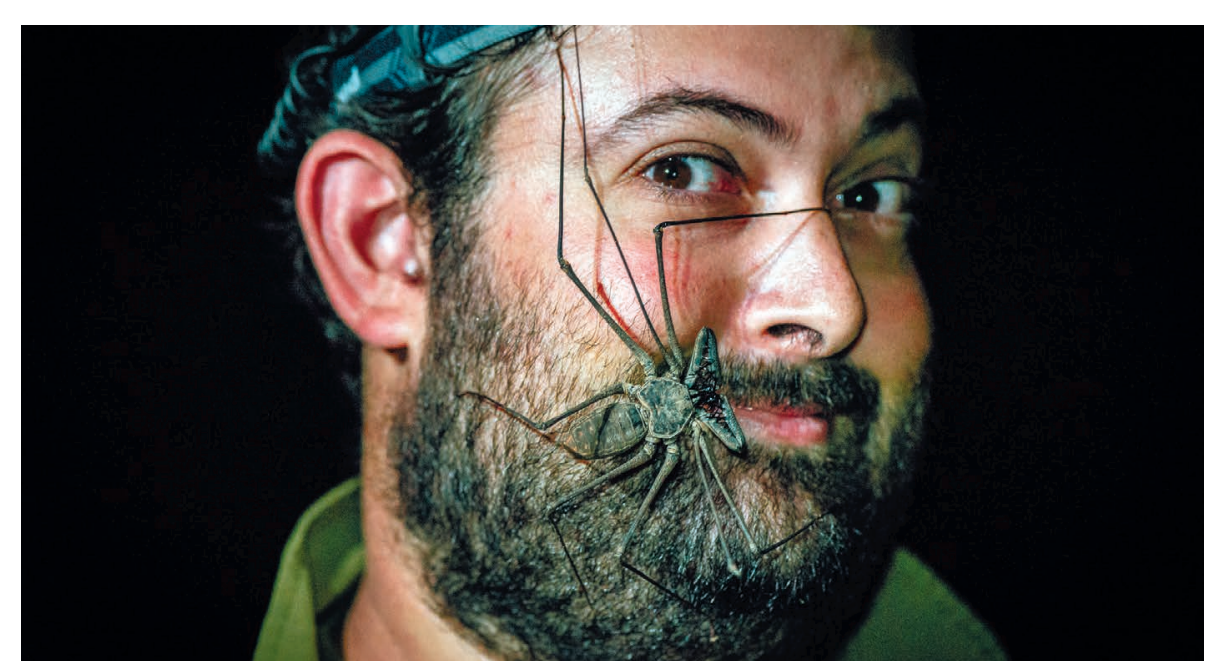

Jason Goldman, a travel guide for Atlas Obscura, proves that tailless whip scorpions are harmless.

\begin{tabular}{l|l|l|lll}
296 & NATURE & VOL 562 & 11 & OCTOBER 2018
\end{tabular}

\section{THE TRAVEL BUG}

\section{How to start as a guide}

Scientists intrigued by travel guiding can try the following short-term options: - Leading local day tours at the weekend or longer trips during the summer. - Volunteering to organize sciencethemed field trips for students.

- Applying to be a guide for

ToursByLocals (see go.nature. $\mathrm{com} / 2 \mathrm{y} 6 \mathrm{asso}$ ), a website that matches local tour guides with travellers.

- Applying for a role as an expedition lecturer on a cruise ship or a naturalist on a whale-watching boat.

- Proposing an idea to a travel company for a trip that provides an opportunity to draw on scientific expertise.

he says. He hopes that the information will encourage people to change their consumer behaviour and choose responsible ecotourism operators for future trips.

\section{TROUBLESHOOTING ON TRIPS}

Travel work involves logistical drudgery. "Anything can go wrong," says Monica Yeung, co-director of the natural-history travel company Gondwana Dreaming in Canberra. "You always have to have plan B, C and D." A bus could break down, bad weather might derail plans or a client may need help arranging an unexpected flight home to attend to a family emergency. Guides should have local contacts to call when plans go awry, Holmes says.

Rude travellers can sour the mood. If one person clashes with the rest of the group, the guide may need to ask them to change their behaviour. "That is never fun," Jackson says. And on the road, trip leaders get few breaks from interacting with clients. "If the customer needs you, you've got to be there," Yeung says.

Scientists also must consider environmental impacts. Irresponsible tour operators can damage habitat, disturb wildlife, pollute waters and leave litter; according to one study, greenhouse-gas emissions from tourism in 2013 made up about $8 \%$ of the world's total emissions (M. Lenzen et al. Nature Clim. Change $8,522-528 ; 2018)$. Some guides minimize impact by keeping their distance from animals, ensuring that waste is removed and instructing travellers to avoid trampling rare plants. To reduce their carbon footprint, they might also stay in lodges with low electricity use or spend more time at fewer stops rather than drive long distances to visit lots of places. Birding Ecotours donates at least $10 \%$ of its profits to conservation initiatives and contributes to programmes that plant native trees.

It is important to ensure that as much revenue as possible returns to locals, Goldman notes. For instance, his tour groups stay at a lodge partly 
owned by a community in Peru. The hope is that tourism will generate an economic incentive for locals to protect wildlife from poaching and the land from other uses, such as mining, logging or agriculture.

Although some guides earn good wages, the work generally isn't lucrative. Jackson says that he makes a comfortable living, but it took about three years for his company to bring in enough money to support himself full-time. Aciego's annual income from her travel company, which occupies about two-thirds of her time, is about half of what she earned as a full-time professor. A starting salary for a scientist joining a travel firm would be slightly less than a postdoc's, and part-time guides earn about US \$100-250 a day, Rollinson estimates. For cruise lecturers, Osinubi says that \$50-200 a day is typical.

And scientists must consider time spent away from home. "The travel is wearing," Aciego says. The job might be difficult for parents; guides tend to be in their $20 \mathrm{~s}$ and 30 s, and those who stay longer often transition to roles with less travel, such as management, Rollinson says. In some cases, scientists might be able to bring family members. Osinubi knows a couple who work as lecturers on cruises together; some cruise lines might allow researchers to bring close family members for limited periods.

Researchers who don't want a full-time travel career can dabble in one (see 'The travel bug'). They could lead day tours at the weekend or longer trips during the summer. Rollinson says his $\mathrm{PhD}$ supervisors did not mind his travel guiding as long as he met research deadlines. Through the website ToursByLocals (see go.nature.com/2y6asso), scientists can apply to guide travellers who are visiting their area, and specify when they are available to give tours. Researchers who are already flying to a remote locale for fieldwork could tack on a nearby trip.

Although being a part-time travel guide might take time away from research, Aciego argues that it is a valid form of science communication. And the work might inform studies. For instance, Osinubi has seen cruise lecturers collect data on animal populations during voyages. Travel guides can build close relationships with locals, who could notify researchers later about environmental changes, Aciego says.

Sharing their knowledge with curious guests often reignites researchers' passion for the subject. Jackson recalls his clients' amazement when he brought them to a mine littered with pyrite crystals in Spain. "I can't even describe how enthused they are," he says. "That wonder that they experience for the first time - I just feed on that. It's a great feeling to be able to do that for people."

Roberta Kwok is a freelance science journalist in Kirkland, Washington.

COLUMN

\section{A truly great mentor}

\section{Hydrogeologist Emma Kathryn White pays tribute to a PhD supervisor who made all the difference.}

$\mathrm{M}$

y PhD supervisor died in June. I'd met with him only days earlier so that he could painstakingly revise my manuscript, giving me several hours of his precious time. He had a way of asking the very questions I didn't want to answer, highlighting the limitations of my work that I'd been trying to hide or skim over. "You need evidence," he'd claim, jabbing a forefinger at one of my many 'unsubstantiated assertions'. He hated those. But he loved a good reference - although not too many for each assertion, mind you.

My supervisor, Justin Francis Costelloe, a geologist and ecohydrologist at the University of Melbourne in Australia, researched arid-zone hydrology for almost 20 years and published more than 80 peer-reviewed papers. He was eminent in his field. But for me, his real impact was in his role as a mentor to students.

Costelloe was big on time management and planning. "Is it feasible, and what is your timeline?" he'd say when I proposed something new. How I loathed preparing timelines. For the first two years of my PhD, in which I am researching groundwater management, I sloppily made them only to appease him. Now, in my third and final year, I make weekly timelines and can barely function without them. As with all great supervisors, accountability was one of Costelloe's strong points. He wanted to make sure that I was doing what I said I was doing, to make sure that I was working.

His calm guidance kept my studies grounded. When my research direction felt like a Picasso painted during the cubist period, he told me to do something I cared about, and to trust that a research question would emerge. His instruction was logical and sequential: don't do too much; use this programme; start here. He lit a path through the fog.

Restructuring articles was also a forte of his. I would present a study like an unshuffled deck of cards, and he would skilfully re-arrange it, putting paragraphs into a logical sequence, transforming the paper into a royal flush.

And he asked why. Always, he was asking me to rationalize things, to simplify, to generalize and explain. "What exactly is your point?" he'd say. But he remained patient, as if it weren't the one-hundredth time he'd asked the same question of me - not to mention of all the students who came before me.

During his career, he'd drilled wells, smashed rocks and tromped through burning deserts. So, he made sure I remembered

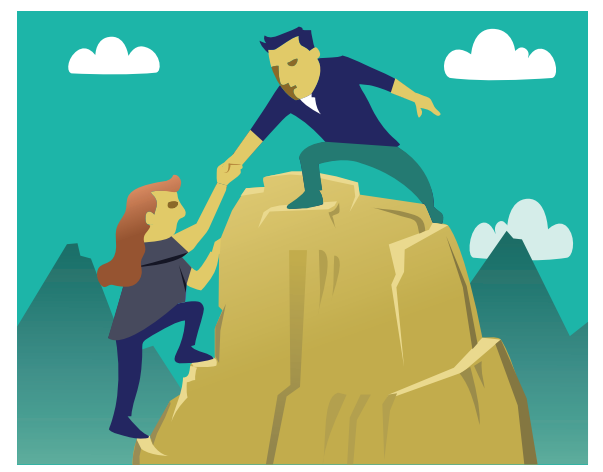

that models can only approximate the infinite complexity of natural systems. "Make sure what the model tells you makes logical sense," he'd say. He saw the complete jigsaw, not just the disconnected pieces.

He'd send me articles that he thought I'd be interested in, and encourage me to attend conferences that would grow my professional network. Mostly, however, he would hassle me about the water budget of my groundwater model. "What are the fluxes?" "What is the model doing?" "Does it make logical sense?" I didn't want to listen, because I was afraid of the equations and code that underpin groundwater models. But when I finally took his advice and opened the Pandora's box of how models really work, my knowledge expanded like a rising loaf.

That's what great mentors do: expand minds.

I wish I had told him the many ways in which he was a truly great $\mathrm{PhD}$ supervisor. He cared about his students. He demanded rigorous science, and led by example. He made sure I was accountable for my time and research direction. He provided guidance and direction, but did not wrap me in cotton wool. He saw the big picture of my PhD: start, middle and (soon, I hope) completion. He looked out for my future career.

His office was littered with rocks, field equipment in various states of disrepair and photos of his beautiful family. But his door was always open. He was my supervisor, yet he treated me like a colleague, valued my opinion and then gently told me why, at times, it was misguided, showing me a better way instead. But mostly he was just a great person, and I feel profoundly grateful to have been his student.

$\mathrm{A} \mathrm{PhD} \mathrm{is} \mathrm{hard.} \mathrm{But} \mathrm{a} \mathrm{good} \mathrm{supervisor} \mathrm{makes}$ it much easier. $\square$

Emma Kathryn White is a PhD student in infrastructure engineering at the University of Melbourne in Australia. 